\title{
WORKERS' ENTERPRISES AND THE TASTE FOR PRODUCTION: THE ARTS, SPORT AND OTHER CASES
}

\author{
Tiziana Cuccia and Roberto Cellini \\ (Università di Catania, Italy)
}

(Final version for the Scottish Journal of Political Economy, September 2008)

\begin{abstract}
This paper shows that the standard result according to which labour-managed firms produce a lower amount of output, as compared to profit-maximising firms, is reversed if production per se gives utility and the workers' membership of labour-managed firms is set prior to market decisions. Under the same hypotheses, the labour-managed firms set a higher product quality than the profit-oriented ones, ceteris paribus. The considered hypotheses are appropriate in several sectors, but they are particularly relevant in the case of the performing arts. (JEL: L23, L82, Z10).
\end{abstract}

ACKNOWLEDGEMENTS: A previous version of this paper was presented at the $14^{\text {th }}$ Acei Conference (Vienna, 2006) and at the $34^{\text {th }}$ Earie Conference (Valencia, 2007); we thank especially Franco Papandrea, David Throsby, and Ruth Towse for their useful comments. We are also grateful for the comments and suggestions of two anonymous referees. The responsibility for any errors is, of course, ours.

\footnotetext{
Corresponding Author: Roberto Cellini Faculty of Economics, University of Catania Corso Italia 55 - 95129 Catania - Italy. Tel. +39-095-7537728. Fax +39-095-7537510. E-mail cellini@unict.it
} 


\title{
WORKERS' ENTERPRISES AND THE TASTE FOR PRODUCTION: THE ARTS, SPORT AND OTHER CASES
}

\author{
ABSTRACT - This paper shows that the standard result according to which \\ labour-managed firms produce a lower amount of output, as compared to \\ profit-maximising firms, is reversed if production per se gives utility and the \\ workers' membership of labour-managed firms is set prior to market \\ decisions. Under the same hypotheses, the labour-managed firms set a higher \\ product quality than the profit-oriented ones, ceteris paribus. The considered \\ hypotheses are appropriate in several sectors, but they are particularly \\ relevant in the case of performing arts. (JEL: L23, L82, Z10).
}




\section{WORKERS' ENTERPRISES AND THE TASTE FOR PRODUCTION: THE ARTS, SPORT AND OTHER CASES}

\section{INTRODUCTION}

It is well-known from the seminal contribution of Ward (1958) that labour-managed (LM) firms -i.e., firms that aim at maximising the per-worker surplus- produce, ceteris paribus, a lower amount of output as compared to profit-maximising (PM) firms. Moreover, LM firms react perversely to exogenous shocks, as compared to PM firms: notably, an increase in the output price, under perfect competition conditions, leads LM firms to restrict their optimal level of production; furthermore, an increase of fixed costs leads LM firms to increase output level (Vanek, 1970).

In the present paper we together consider two different critical points that have been directed at the standard literature on LM firms.

Firstly, Sertel $(1982,1987)$ suggests that the distortions in LM firms' behaviour are generated by the assumption that the labour input is a choice variable, i.e., the size of membership is determined at the same time as the output amount. According to Sertel, this assumption is far from being realistic: on the contrary, the membership of LM firms (i.e., the labour input) is set before the market decisions are taken. Under this hypothesis, LM firms are relabelled as workers' enterprises (WE). In this case, the LM firm replicates the behaviour of the PM firm, and its alleged perverse behaviour, as compared to the PM firm, indeed disappears. This happens irrespective of the intensity of market competition (see also Sertel, 1991, 1993, Fehr and Sertel, 1993). A great deal of empirical evidence supports the idea that labour input is sticky, if not fixed, in LM firms - see, e.g., the reviews by Bonin et al. (1993, Section 5) or Moretto and Rossini (2003).

Secondly, Cellini and Cuccia (2003) show that LM firms may produce a larger amount of output than PM firms, at any given regime for the output market, if production per se provides utility.

Of course, the idea that production per se (or work) provides positive utility is not new: already Jevons in his 1871 Theory of Political Economy suggested such a point. 
Recently, several contributions have suggested that many groups of persons are likely to derive satisfaction from their work in itself and not just from the monetary income derived - experimental scientists, researchers and academics, doctors, lawyers, people in professional sports, and so on (see Frey and Stutzer, 2002; Ward and Sloane, 2000, on academics; Glazer, 2004, and Francois, 2000, 2003, on workers in public services; Zimbalist, 1992, and Vrooman, 2000, 2007 on sportsmen). We could also argue that all jobs may contain both positive and negative elements and there is a continuum of degrees of taste for production per se in different jobs and different sectors. The recent literature on devoted workers (Tirole and Benabou, 2006) provides further evidence confirming this consideration.

In the present paper we study the optimal choices of LM firms, taking into consideration the two aforementioned points together: specifically, we consider the case in which the labour input is not a choice variable for firms (that is, the labour input or the membership of LM firm is considered as given), and the output production in itself provides utility.

Under these simultaneously considered hypotheses, LM firms (or rather, WE firms) produce a larger amount of output as compared to corresponding PM firms. This result holds under both perfect competition conditions and the monopoly case. Under the same hypotheses, a clear-cut result also emerges with respect to the quality of production: LM firms find it optimal to set a strictly higher quality of output, as compared to the corresponding PM firms, irrespective of the market competition regime. It is worth underlining this result, given that available theoretical models provide mixed results as concerns product quality set by LM firms (see Martin, 1986, vs. Lambertini, 1997).

Our interest in LM firms is motivated not only by the incidence of this specific form of firms (proper LM firms are less than 2\% of all registered firms and account for about $2-2.5 \%$ of employment in most of the developed countries), but also by the incidence of very similar types of enterprises, in different environments. In particular, there are strong similarities between LM firms and the so-called non-employer firms, i.e., entrepreneurial firms, where the owners are the only workers (Rossini, 2005; Aoki and Takizawa, 2002). In the world of co-determination firms, there are many enterprises, for instance in Germany or Sweden, which behave in a manner that closely mimics LM firms, 
that is, they aim to maximise the surplus per worker (Levinson, 2000; Gorton and Schmid, 2000). Similar considerations hold also for the firms with ESOP (Employee Stock Ownership Plans), and for the so-called "J-firms" (or Japanese firms), in which workers participate in the firm's decisions but they do not have any stake in the property - see the wide-ranging discussion in Bonin et al. (1993). Also, in transition countries, there are many firms (not just of medium-small size) whose internal organization is LM or very close to it, as documented in the book edited by McIntyre and Dallago (2003).

The subjects we are considering -that is, LM or similar firms in which the taste for production per se" is important and in which the labour input has to be considered as fixed prior to market decisions- are significant in a number of different sectors, like health care, education, professional sport, and professional services.. For our present purpose, we will take the arts sector of as the prominent example: according to several authors, the love of suppliers for their productions is the most remarkable feature of the arts sector (Caves, 2000; Candela and Scorcu, 2004, Chs. 4 and 9); the substitution of worker-artists is very difficult (for instance in symphony orchestras, as documented by Caves, 2000, Ch. 14 and 15), so that the membership of LM can be considered exogenous; the spread of LM firms is significant (as will be documented below). Here, the presence of LM firms should be particularly welcomed, since it means larger quantity and higher quality of output as compared to the choice made by PM firms.

The remainder of the paper develops as follows. Section 2 briefly presents a few relevant points made by available models. Section 3 shows the core result of the paper concerning the amount of output production. Section 4 deals with the choice concerning product quality. Section 5 discusses the results and offers our conclusion, also taking in to account some preliminary evidence concerning the spread of cultural LM firms.

\section{LITERATURE}

Consider the case in which production takes place according to the following production function, in which $Q, L$ and $K$ respectively denote output, labour input and capital input: 


$$
Q=Q(L, K) \quad, \quad Q_{i}^{\prime}>0, Q^{\prime \prime}{ }_{i}<0, i=L, K
$$

and $p, w$ and $r$ are the price of $Q, L$ and $K$, respectively.

Under perfect competition conditions, the PM firm aims at maximising the following objective function

$$
\pi=p \cdot Q(L, K)-w L-r K
$$

while the LM firm aims at maximising the surplus per worker, that is, what remains for each worker, after the $K$ input is paid ${ }^{1}$ formally, the LM firm maximises the following function:

$$
y=\frac{p Q(L, K)-r K}{L}
$$

If $K$ is fixed $(K=\bar{K})$, so that a fixed cost entails, $F=r \bar{K}$, and $L$ is the choice variable, it is easy to show that the LM firm produces a lower amount of output compared to the corresponding PM firm (provided that the profit of the PM firm is positive). ${ }^{2}$ Moreover, the LM firm reacts to an exogenous increase in fixed costs, by increasing the level of production (unlike the PM firm, which maintains the level of production constant) and reacts to an exogenous increase in the output price, by decreasing its optimal level of production (again, unlike the PM firm which finds it optimal to increase its level of

\footnotetext{
${ }^{1}$ Notice that the labour input coincides with the membership of the LM firm, and each worker offers a constant amount of labour. Models that remove these assumptions are, e.g., Ireland and Law (1982) or Bonin and Putterman (1987).

${ }^{2}$ The result derives from the first order condition (FOC) with respect to $L$, computed on objective functions (2) and (3). The FOCs lead to $Q^{\prime}{ }_{L}=w / p$ and $Q^{\prime}{ }_{L}=(p Q-F) /(L p)$, for PM firms and LM firms, respectively. Since $[(p Q-F) / L]>w$ (provided that profit of the PM firm is positive), and provided that $Q^{\prime}{ }_{L}$ is decreasing in $L$, the optimal amount of labour employed by the PM firm (and hence its level of production) is larger than the optimal level for the LM firm (see Ward, 1958; Vanek, 1970).
} 
production). ${ }^{3}$ The intuition is straightforward: a LM firm is interested in per-worker surplus and finds it convenient to restrict its labour input (i.e., its worker membership), and hence its production level, as compared to a PM firm. Moreover, LM firm reacts to adverse shocks (e.g., an increase of fixed costs or a decrease of output price) by enlarging membership and hence production.

Analogous considerations hold if a firm sells its product in monopoly or oligopoly markets. If, for instance, the output market is a monopoly, the price of output is no longer the parameter $p$, but it is given by the function

$$
P=P(Q), \quad P_{Q}^{\prime} \equiv d P(q) / d Q<0 .
$$

In such a case, under the hypothesis that the input labour is the choice variable (with a given amount of capital input), the comparison of conditions of optimality for the PM firm and the LM firm easily leads to the conclusion that the amount of labour input for the PM firm is larger. ${ }^{4}$

As already mentioned, Sertel $(1982,1987)$ argues that it is unrealistic to believe that the amount of labour, and especially the membership of a LM firm, is endogenous: rather, it is pre-determined, since significant membership constraints to entry and exit are indeed operative in the real world, and "markets for memberships" do not exist. In other words, Sertel questions the assumption that labour input can be endogenously determined with production levels by firms; he considers instead the case in which labour input is predetermined, so that the choice variable is the level of capital. Sertel labels the labourmanaged firms facing exogenous membership as workers' enterprises (WE). In this circumstance, he finds that the optimal behaviour of the WE coincides with the optimal behaviour of the PM firm.

\footnotetext{
${ }^{3}$ These results immediately derive from the application of the implicit function theorem to the FOCs.

${ }^{4}$ First order conditions for the PM firm and the LM firm in monopoly are respectively, $Q_{L}^{\prime}()=.(w / p) /\left(1+1 / \varepsilon_{Q, P}\right)$ and $Q_{L}^{\prime}()=.\{[(p Q()-F) / L] / p\} /.\left(1+1 / \varepsilon_{Q, P}\right)$, where $\varepsilon_{Q, P}$ denotes the price elasticity of the market demand. See Hill and Waterson (1983), Cremer and Cremer (1982) among others for the analysis of LM firms in oligopoly markets.
} 
To prove the theoretical result obtained by Sertel, it is sufficient to consider equations (2)-(3), imposing $L=\bar{L}$ (with $\bar{L}>1$ as a constant parameter), and to solve the optimisation problems with respect to $K$. Under both the case of PM firms, and the case of WE, the optimal choice is such that $Q^{\prime}{ }_{K}=r / p$. Thus, PM firms and WE firms are identical as regards the optimal choice, and hence the reaction to exogenous shocks. This result also holds irrespective of the competition regime in the output market. ${ }^{5}$

In conclusion, when the firms' choice variable is no longer the labour input, but inputs other than labour, LM firms behave in the same way as PM firms. There is empirical evidence to support these ideas, that is, that labour is fixed prior to market decisions, and similar reactions to the same shock characterise LM and PM firms (Bonin et. al., 1993; Craig and Pencavel, 1995).

A (different) well-known theoretical result, originally suggested by Meade (1972), is that an economy populated by LM firms would replicate the Walrasian allocation of an economy populated by PM firms, if a proper market for LM membership existed (see Dow, 1996, for an analytical proof). However, there is a wide body of economic (and sociological) literature on labour-managed firms showing that the entry to (as well as the exit from) the membership of a LM firm is difficult (Dow, 1986; Moretto and Rossini, 2003; Caves, 2000, Chs. 14 and 15 with specific reference to the performing arts sector). This means that the LM membership in the short run is at least a sticky (if not fixed) variable, and the point made by Sertel has clear empirical relevance.

The standard results on the perverse behaviour of LM firms are questioned not only when one assumes that the workers' membership is exogenous, but also under different circumstances.

For instance, maintaining the assumption that labour is the choice variable for firms (that is, the membership of the LM firm is endogenous), Cellini and Cuccia (2003) analyse the case in which the production per se provides satisfaction (or utility).

\footnotetext{
${ }^{5}$ If, for instance, the output market is a monopoly, under the demand function (4), the profit is: $\pi=P(Q(K, \bar{L})) \cdot Q(K, \bar{L})-w \bar{L}-r K, \quad$ while the surplus per-worker is $y=[P(Q(K, \bar{L})) \cdot Q(K, \bar{L})-r K] / \bar{L}$, and the corresponding FOCs (w.r.t. $K$ ) coincide.
} 
Let $v=v(Q)$ denote the monetary measure of utility provided by the production per se of good $Q$, with $v_{Q}^{\prime} \equiv d v(Q) / d Q>0$. Under such a hypothesis, a profit-oriented firm (with taste for production) maximises a function like $V^{a a}=V^{a a}(\pi, v(Q))$ while a LM firm maximises a function like $y^{a a}=y^{a a}(y, v(Q))$ where superscript $a a$ denotes "taste for production" (or love for arts, in the specific example of arts production). For the sake of convenience, let us assume additive separable functions, so that profit-oriented and LM firm respectively maximise:

$$
\begin{aligned}
& V^{a a}=p \cdot Q(L, K)-w L-r K+\alpha v(Q(L, K)) \\
& y^{a a}=\frac{p Q(L, K)-r K}{L}+\beta v(Q(L, K))
\end{aligned}
$$

where $\alpha \geq 0$ and $\beta \geq 0$ are preference parameters capturing the importance of the production per se into the objective functions. The profit-oriented firm which aims at maximising function (5) will be labelled here as "quasi-PM" .

Note that function (5) is formally similar to the objective function considered by Vickers (1985) for a managerial firm in which managers have a taste for output expansion or have production incentives. Along this line, function (6) could be interpreted as the objective function of a LM firm that has hired a manager with taste for production or who benefits from production incentives. ${ }^{6}$

We are here interested in showing that it is no longer necessarily true that a LM firm produces a lower level of production as compared to the corresponding quasi-PM firm, if $\alpha$ and $\beta$ are strictly positive. The proof is immediate. From the FOCs w.r.t. $L$

\footnotetext{
${ }^{6}$ Classical references concerning managerial firms are Baumol (1959) or Williamson (1964); Vickers (1985), in particular, suggests considering the objective function of a managerial firm as a weighted average of profit and production. In the literature that has derived from Vickers, parameter $\alpha$ (and $\beta$ ) can be fixed strategically by owners, in order to lead managers to behave in specific ways; however, we disregard these aspects in the present paper. For a specific contribution on the role of non-monetary motivation of managers, see Frey and Osterloh (2005).
} 
computed on functions (5) and (6) with $K=\bar{K}>0$ and hence $F=r \bar{K}>0$, we respectively obtain:

$$
Q_{L}^{\prime}(.)=\frac{w}{p+\alpha v_{Q}^{\prime}}
$$

$$
Q_{L}^{\prime}(.)=\frac{p Q(.)-F}{L} \cdot \frac{1}{p+\beta L v_{Q}^{\prime}}
$$

Comparing (7) with (8), we immediately realise that the LM firm may produce either a larger or a smaller amount of output as compared to the quasi-PM firm, depending on parameters $\alpha$ and $\beta$ and the sign of the second derivative of $v(Q){ }^{7}$ Note that it is not sufficient that the utility from production per se exists, in order to conclude that the LM firm produce a larger output than the profit-oriented firm: this is simply a possibility, depending on the parameter configuration.

Some immediate implications follow: in the case that production per se provides utility, it is no longer necessarily true that a LM firm reacts to an increase in fixed costs by increasing the level of production (as happens in the case of a standard LM firm). Moreover, it is no longer necessarily true that a LM firm (with utility from production per $s e)$ reacts to an increase in the output price by decreasing the level of output. ${ }^{8}$ In particular, the "perverse" reaction of the LM firm to exogenous shocks depends on specific parameter conditions.

It is clear that the point made by Sertel -i.e., labour is set prior to market decisions - and the point made by Cellini and Cuccia - production in itself provides utilityare not mutually exclusive. The case in which both assumptions hold together is analysed in the next section.

\footnotetext{
${ }^{7}$ For instance, if $v^{\prime \prime} Q^{=} 0$ and $v^{\prime}{ }^{\prime}=v>0$, the LM firm produces a larger amount of output than the PM firm if $w /(p+\alpha v)>[p Q()-F] /.[L(p+\beta L v)]$.

${ }^{8}$ The corollaries can be easily proved by applying the implicit function theorem to (7).
} 


\section{WORKERS' ENTERPRISES WITH TASTE FOR PRODUCTION}

Consider a firm facing a constraint on the amount of labour input to be used for production, under the case in which the per se production of output provides utility. This means that -under perfect competition conditions- the (quasi)-PM firm maximises the following objective function:

$$
V^{a a}=p \cdot Q(\bar{L}, K)-w \bar{L}-r K+\alpha v(Q(\bar{L}, K)), \quad \alpha \geq 0
$$

while the corresponding WE maximises the function:

$$
y^{a a}=\frac{p Q(\bar{L}, K)-r K}{\bar{L}}+\beta v(Q(\bar{L}, K)), \quad \beta \geq 0
$$

As already mentioned, these assumptions are particularly appropriate in the case of the production of arts goods, and more specifically in the case of the performing arts: a wide body of available theoretical models suggest that the production per se of such goods provides utility: see, e.g., Throsby (1994a,b), Frey (1997), Caserta and Cuccia (2001), Papandrea and Albon (2004), and particularly Caves (2000), who stresses the love of suppliers for their productions as the most remarkable feature of the arts sector. Moreover, the membership entry-exit processes are quite difficult in this field, as documented, e.g., by Caves (2000, Chs. 14 and 15) for the case study of American orchestras. Ultimately, a market for membership in LM firms could be particularly useless for the performing arts, since aggregation among artist-workers in firms can hardly be determined by market mechanisms in this peculiar sector. Similar considerations, however, can obtain in different fields - for example, professional sports, ${ }^{9}$ education, health, and professional services.

Maximisation of function (9) regarding quasi-PM firm implies

\footnotetext{
${ }^{9}$ For an analysis of similarities between LM firms and professional sports clubs see Szymanski and Ross (2002).
} 


$$
Q_{K}^{\prime}(\bar{L}, K)=\frac{r}{p+\alpha v_{Q}^{\prime}}
$$

while maximisation of function (10) regarding the corresponding WE with taste for production implies

$$
Q_{K}^{\prime}(\bar{L}, K)=\frac{r}{p+\bar{L} \beta v_{Q}^{\prime}}
$$

The conclusion about the comparison between the optimal choices of profitoriented firm and workers enterprise (both with taste for production) depends on the relationship between $\alpha$ and $\bar{L} \beta$. It appears to be natural to assume:

$$
\alpha<\bar{L} \beta
$$

Under this assumption, ${ }^{10}$ the optimal level of capital input used by the WE firm turns out to be larger than the optimal level of capital used by the profit-oriented firm. ${ }^{11}$ Consequently, the level of production is larger for WE.

${ }^{10}$ Condition (13) is obvious, provided that the love for arts by part of workers involved in their production is presumably larger than the love for arts of a profit-oriented capitalist $(\alpha<\beta)$. In any case, even if the love for arts were the same $(\alpha=\beta)$, condition (13) is fulfilled as long as $\bar{L}>1$. It is clear that when $\bar{L}=1$ and $\alpha=\beta$, the choices made by the quasi-PM firm and the corresponding WE coincide: in fact, the profit or the individual surplus for the one-person firm coincide. Note that a scale effect is present in the problem of the LM firm, since the function $v($. conceptually denotes the utility derived by one worker; in the objective of the quasi-PM firm, $v($. is conceptually referred to the profit-maximising agent. Of course, the scale effect would disappear if either $v($.$) were multiplied by L$ in the objective of the PM firm, or divided by $L$ in the LM problem.

${ }^{11}$ If $\alpha<\bar{L} \beta$, then $r /\left(p+\alpha v_{Q}^{\prime}\right)>r /\left(p+\beta \bar{L} v_{Q}^{\prime}\right)$ and hence the marginal productivity of capital input has to be equal to a larger amount in the case of a profit-oriented firm, as compared 
This conclusion also holds in the case of monopoly in the output market. In such a case, the market demand function (4) has to be considered instead of parameter $p$, in the objective functions (9) and (10). The corresponding FOC for a monopolistic profitoriented firm is

$$
\left(P_{Q}^{\prime} \cdot Q+P+\alpha v_{Q}^{\prime}\right) Q_{K}^{\prime}(\bar{L}, K)=r
$$

while the FOC for the monopolistic WE is

$$
\left(P_{Q}^{\prime} \cdot Q+P+\bar{L} \beta v_{Q}^{\prime}\right) Q_{K}^{\prime}(\bar{L}, K)=r
$$

In this case, with condition (13) still applying, it immediately follows that the WE produces a larger amount of output than the profit-oriented firm. ${ }^{12}$ Clearly, in the case of a monopolistic output market, the presence of WE firms is thus able to reduce the deadweight loss associated with the PM firm.

\section{THE CHOICE ON PRODUCT QUALITY}

The available literature on the choices made by the different types of firm concerning product quality is rather limited. However, some authors, examining the question from a sociological perspective, argue that the structure of LM firm leads to higher quality effort per member, which entails higher product quality. Along these lines, the differences in output quality across different types of firms are rooted in the differences in worker motivation, and the evidence supporting the argument are generally heuristic or anecdotal

to the corresponding WE firm. This requires a smaller amount of optimal capital input for the quasi-PM firm, given the decreasing marginal productivity hypothesis.

${ }^{12}$ The proof is straightforward: WE has to equate $Q^{\prime}{ }_{K}$ to $r /\left(P^{\prime}{ }_{Q} \cdot Q+P+\bar{L} \beta v^{\prime}{ }_{Q}\right)$, which is smaller than $r /\left(P^{\prime}{ }_{Q} \cdot Q+P+\alpha v^{\prime}{ }_{Q}\right)$ for any given level of $K$. Provided that $Q{ }_{K}$ is decreasing in $K$, the conclusion follows. 
(see various contributions in Stephen, 1982). Unfortunately, econometric analyses of the product quality set by LM firms are not available, to the best of our knowledge. ${ }^{13}$

Within the theoretical literature on the product quality choices of LM firms, Martin (1986) proposes a model under the assumption that worker motivation is the same across different types of firms, and finds that LM firms choose higher product quality than PM firms, provided that quantity and quality are perfect substitutes in the service flow derived by consumers from the considered product, and production costs are linear in quantity. On the other hand, Lambertini (1997) finds that the (standard) LM firms not only produce a smaller amount of output quantity, as compared to PM firms, but also set a lower quality, if the quality of product is a choice variable entailing increasing marginal cost; ${ }^{14}$ this result, however, is no longer clear-cut if one considers non-standard distributions of consumers over the interval for quality premium (Celada and Lambertini, 2006). The output quality of LM firms relative to PM firms proves to be ambiguous also in the case in which production per se provides satisfaction and the labour input is a choice variable for firm (Cellini and Cuccia, 2003).

In this Section we show that a clear-cut theoretical result obtains, under the simultaneous assumptions that (i) production per se provides utility, and (ii) the labour input is set prior to output decisions. Under these assumptions, a LM firm finds it optimal to set a higher level of quality as compared to a profit-oriented firm, ceteris paribus.

We have preferred in this case not to consider the problem concerning the possibility of objectively observing the quality of a good, even if this point is particularly important in the case of arts production - see, e.g., Towse (1997). Following a suggestion

\footnotetext{
${ }^{13}$ While there are a few econometric analyses of the productivity performances of LM firms as compared to PM ones, the specific issue of product quality has been overlooked so far. The empirical evidence related to productivity -though mixed- seems to suggest that LM firms could perform better in the short run, while worse performances prevail in the long run - see Pencavel and Craig (1994), Craig and Pencavel (1995), Estrin (1991); see also the review by Moretto and Rossini (2003).

${ }^{14}$ This strand of literature generally considers (standard) industrial-organization models with vertically differentiated goods (like Spence, 1975, or Mussa and Rosen, 1978) and substitutes the hypothesis of profit maximization with the assumption of per-worker surplus maximization.
} 
by Hansman (1981), we simply assume that a firm can decide the number of units of output, $n$, and their quality $q$, which is assumed to be observable. Moreover, the unit price of output is given by the following inverse market demand function:

$$
P=P(n, q) \quad, \quad P_{n}^{\prime}=\partial P / \partial n<0, P_{q}^{\prime}=\partial P / \partial q>0
$$

Clearly, function (16) requires that product quantity and quality are substitutes for consumers: such an assumption, though questionable, is common to the whole mentioned literature. The production of output units and output quality can be represented through the following production functions:

$$
\begin{aligned}
& n=n(L, K) \quad, \quad n_{L}^{\prime}=\partial n / \partial L>0, \quad n_{K}^{\prime}=\partial n / \partial K>0 \\
& q=q(I)=I
\end{aligned}
$$

where $I$ denotes effort for quality, which entails quadratic cost, i.e.,

$$
c(I)=b \cdot I^{2} \quad, \quad b>0
$$

Within this framework, a profit-oriented firm with taste for production in itself maximises the objective function

$$
V^{a a}=P(n(L, K), q) \cdot n(L, K)-w L-r K-b I^{2}+\alpha v(n(L, K), q)
$$

while the LM firm maximises

$$
y^{a a}=\frac{P(n(L, K), q) \cdot n(L, K)-r K-b I^{2}}{L}+\beta v(n(L, K), q)
$$

Let us start by considering the (standard) case that both $L$ and $I$ are choice variables, while $K$ is given (see Cellini and Cuccia, 2003). The optimum for PM and LM firms respectively implies: 


$$
\begin{aligned}
& n_{L}^{\prime}=\frac{w / P}{1+\varepsilon_{P, n}+\left(\alpha v_{n}^{\prime} / P\right)} \quad, \quad I=\frac{P_{q}^{\prime} \cdot n+\alpha v_{q}^{\prime}}{2 b} \\
& n_{L}^{\prime}=\frac{\left[\left(P n-b I^{2}-r \bar{K}\right) / L\right] / P}{1+\varepsilon_{P, n}+\left(\beta L v_{n}^{\prime} / P\right)} \quad, \quad I=\frac{P_{q}^{\prime} \cdot n+\beta L v_{q}^{\prime}}{2 b}
\end{aligned}
$$

where $\varepsilon_{P, n}$ denotes the price elasticity to the number of output unities.

Comparing (22) and (23), it is immediately clear that:

a) if production per se does not provide utility i.e., $\alpha=\beta=0$ (so that we fall within the "standard" model of LM firm with endogenous choice of labour input), the number of output units sold by a PM firm is larger than the optimal number for the corresponding LM firm, provided that the profit of the PM firm is positive, i.e. $\left(P n-b I^{2}-r \bar{K}\right) / L>w$. In symbols, $n^{P M}>n^{L M}$. In turn, the optimal efforts in product quality, and the product quality itself, are larger for the PM firm as compared to LM firm, given that $P^{\prime}{ }_{q} n^{P M} /(2 b)>P^{\prime}{ }_{q} n^{L M} /(2 b)$.

b) if production per se provides utility, it is no longer necessarily true that profitoriented firm sets larger $n$ and $I$ than LM firms, and the relationship between $n^{P M}$ and $n^{L M}$, as well as the relationship between their respective efforts in product quality, become ambiguous a priori.

However, if we consider the case that the labour input is set before the market decisions are taken, so that $L$ becomes a constant, while the choice variables are $K$ and $I$, the optimum conditions for PM and LM firm respectively are:

$$
\begin{aligned}
& n_{K}^{\prime}=\frac{r}{P_{n}^{\prime} n+P+\alpha v_{n}^{\prime}} \quad, \quad I=\frac{P_{q}^{\prime} \cdot n+\alpha v_{q}^{\prime}}{2 b} \\
& n_{K}^{\prime}=\frac{r}{P_{n}^{\prime} n+P+\beta L v_{n}^{\prime}} \quad, \quad I=\frac{P_{q}^{\prime} \cdot n+\beta L v_{q}^{\prime}}{2 b}
\end{aligned}
$$


Comparing (24) and (25), we can immediately verify that:

a) if production per se does not provide utility, i.e., $\alpha=\beta=0$ (so that we fall within the model of WE firm à la Sertel), the WE and the PM firms choose the same optimal amount of capital, and hence produce the same quantity of output. Also the efforts for quality, and product quality itself, are the same for both types of firms.

b) if production per se provides utility, and condition (13) holds, the marginal productivity of capital at equilibrium has to be larger for the quasi-PM firm as compared to the corresponding WE. As a consequence, the optimal amount of capital for the quasi-PM firm is smaller than the optimal amount of capital for the WE; hence, the amount of production optimal for the profit-oriented firm is smaller as compared to the optimal amount for the WE. As far as the efforts for product quality are concerned, it is immediate to see that the optimal efforts for a profit-oriented are smaller than the optimal efforts for a WE, thanks to (13), and hence the product quality chosen by a WE firm is higher than the quality chosen by the corresponding profit-oriented firm, ceteris paribus.

In sum, LM firms find it optimal to produce a larger amount of output, and to set a higher quality of output, as compared to profit-oriented firms, if they face a pre-market constraint on their labour membership, and the per se production of good provides utility. The economic explanation is simple: under the considered circumstances, the marginal benefits from increasing the quantity and the quality of output are larger for labour-managed firms, as compared to profit-maximising firms, while the marginal costs are the same for both types of firms. In particular, the larger amount of output chosen by WE is explained by the higher satisfaction from production in itself, conjoined with the fact that it is impossible to reduce the number of members who share in the benefits, since the workers' membership is assumed to be given. 


\section{DISCUSSION AND CONCLUDING REMARKS}

In this paper we have shown that the standard result that labour-managed firms find it optimal to produce a smaller amount of output as compared to profit-maximising firms is reversed, when production per se gives utility and the size of workers' membership is set before the market decisions are taken. Under the same assumptions, a clear-cut result emerges, concerning output quality: labour-managed firms find it optimal to set a higher product quality, as compared to profit-oriented firms.

We have chosen to refer to the case of arts as an example. The two mentioned hypotheses are particularly appropriate for the performing arts sector. Here, (i) the per se production of output provides satisfaction; (ii) the amount of labour to be used for production is hardly interpretable as a choice variable, both because labour is hardly substitutable by other inputs, and because the specific qualification of workers makes the existence of a market for the LM firm membership difficult (if not impossible). Hence, we have argued that in this sector the presence of workers' enterprises has to be particularly welcomed, since their presence does not entail the market inefficiencies usually associated with labour-managed firms in standard industrial sectors.

Perhaps it is not a coincidence that the presence of LM firms is more intense in the cultural sector than other sectors. Even if statistical data are difficult to collect (and to compare across countries, especially because of differences in the registration and classification of firms) some evidence can be mentioned. In Italy, for instance, cooperative firms (the legal form of firms nearest to LM) represent $1.4 \%$ of registered firms, but in the class of "various services" (the category in which cultural firms enter), the percentage goes up to $5.6 \%$ (just behind the highest percentage, in the class of "education and health"). ${ }^{15}$ In Sicily, the region where we checked the individual registration of firms in the formal register of companies ("Registro delle imprese"), cooperatives are $2.4 \%$ of all firms, but the percentage is around $9 \%$ if we focus on firms operating in cultural fields. Different Italian regions (like Emilia Romagna in the North) share similar data. ${ }^{16}$

\footnotetext{
${ }^{15}$ Data are from Unioncamere (2004) and are referred to June 2004.

${ }^{16}$ A comprehensive research on the spread of cultural LM firms is in our research plans. Up-date data on the spread of cooperative firms are available on many websites; see, e.g., the site of the
} 
Furthermore, similar evidence comes from US data. Let us consider the US nonemployer firms, i.e., firms of owner-workers, who are on an equal footing; this type of enterprise is clearly close to LM firms, at least as concerns their possible goals. The ratio between the non-employer and the employer firms is $3.4: 1$ if considered on the basis of the total number of firms, but the ratio increases to $8.5: 1$ if we consider only the sector of arts, entertainment and recreation (Data from US Census referred to 2005). ${ }^{17}$

However, the taste for production in itself also occurs in different sectors, such as education and health or professional sport, and in different cases (e.g., in the presence of a managerial incentive). Furthermore, constraints to labour input are present in many cases, and the absence of a proper market for the participation in the membership of labourmanaged firms is the rule rather than the exception. Thus, our conclusion that LM firms produce a larger amount of output, and set a higher product quality, than the corresponding profit-maximising firms is likely to extend well beyond the arts sector.

We close the paper with a cautionary note: the present model does not consider additional elements worth analysing. ; some of the more significant would be: the distortions in the individual incentives for workers (Kremer, 1997); the distortion in investment in productive capacity (Futagami and Okamura, 1996; Lambertini and Rossini, 1998) or in R\&D for process innovation (Lambertini, 1998); the different objectives chosen by the LM firm (see Oczkowski, 2006); the determination of the initial size of the firm. These issues are part of our plans for future research.

University of Wisconsin Centre for Cooperatives with its links, or the site of the Committee for the Promotion and Advancement of Cooperative by COPAC (a project joining UN, ILO, FAO among other institutions).

${ }^{17}$ Based on the US Census, Rossini (2005) reports that in 2001 the Non-employer firms were $16,979,498$ in the US vis à vis 7,095,302 of the Employer category. Subsequently data have been slightly revised by US Census, but the meaning remains unchanged: the most recent data, referred to 2005, count 20,392,068 Non-employer firms vs. 5,983,546 Employer firms. 


\section{REFERENCES}

Aoki M - H. Takizawa (2002), "Information, incentives, and option value: the silicon valley model", Journal of Comparative Economics, 30, 759-786.

Baumol W. J. (1959), Business Behaviour, Value and Growth, MacMillan, London.

Ben Ner A. (1988), "Comparative Empirical Observations on Worker-Owned and Capitalistic Firms", International Journal of Industrial Organization, 6, 7-32.

Bonin J. - D.C. Jones - L. Putterman (1993), "Theoretical and Empirical Studies of Producer Cooperatives: Will Ever the Twain Meet?", Journal of Economic Literature, 31, 1290-1320.

Bonin J. - L. Putterman (1987) Economics of Cooperation and The Labor-managed Economy, Harwood Academic Publishers, New York.

Candela G. - A.E. Scorcu (2004), Economia delle Arti, Zanichelli, Bologna.

Caserta M. - T. Cuccia (2001), The Supply of Arts Labour: Towards a Dynamic Approach, Journal of Cultural Economics, 25, 185-201.

Caves R.E. (2000), Creative Industries: Contracts between Art and Commerce, Harvard University Press, Cambridge, MA.

Celada C. - L. Lambertini (2006), "Quality Distorsion in a Labour-Managed Monopoly", in Lambertini L. (Ed.) The Economics of Vertically Differentiated Markets, Edward Elgar, Cheltenham.

Cellini R. - T. Cuccia (2003), "Le peculiarità delle imprese cooperative nel settore dell'arte: Un'analisi teorica", Rivista di Politica Economica, 93, 35-65.

Craig B. - J. Pencavel (1995), "Participation and Productivity:A Comparison of Workers Cooperatives and Conventional Firms in the Plywood Industry", Brooking Papers on Economic Activity - Microeconomics, 121-174.

Cremer H. - J. Cremer (1992), "Duopoly with Employee-Controlled and ProfitMaximizing Firms: Bertrand vs Cournot Competition", Journal of Comparative Economics, 16, 241-58.

Dow G. K. (1986), "Control Rights, Competitive Markets and Labor Management Debate", Journal of Comparative Economics, 10, 48-61.

Dow G. K. (1996), "Replicating Walrasian Equilibria Using Markets for Membership in Labour-Managed Firms", Economic Design, 2, 147-62. 
Fehr E. - M. Sertel, (1993), "Two Forms of Workers Enterprises Facing Imperfect Labor Markets", Economics Letters, 41, 121-27.

Francois P. (2000), "Public Service Motivation as an Argument for Government Provision", Journal of Public Economics, 78, 275-99.

Francois P. (2003), "Not-for-profit Provision of Public Services ", Economic Journal, 113, C53-61.

Frey B. S. (1997), Not Just for the Money, Edward Edgar, Cheltenham.

Frey B. S. - A. Stutzer (2002), “What Can Economists Learn from Happiness Research?”, Journal of Economic Literature, 40, 402-35

Frey B. S. - M. Osterloh (2005), "Yes, managers Should Be Paid like Bureaucrats", Journal of Management Inquiry, 14, 96-111.

Futagami, K. - M. Okamura (1996), "Strategic Investment: The Labor-Managed Firm and the Profit-Maximizing Firm", Journal of Comparative Economics, 23, 73-91.

Glazer A. (2004), "Motivating Devoted Workers ", International Journal of Industrial Organization, 22, 427-40.

Gorton, G. - Schmid, F. (2000), "Class struggle within the firm: a study of German codetermination”, NBER Working Paper 7945, Cambridge, MA.

Hansmann H. (1981), "Nonprofit Enterprise in the Performing Arts", Bell Journal of Economics, 12, 341-61.

Hill M. - M. Waterson (1983), "Labour-managed Cournot Oligopoly and Industry Output", Journal of Comparative Economics, 7, 43-51.

Kremer M. (1997), "Why are Cooperatives so rare?", NBER working paper 6118.

Ireland N. - P. Law (1982), The Economics of Labor Managed Enterprises, Croom Helm, London.

Lambertini L. (1997), On the Provision of Product Quality by a Labour-managed Monopolist, Economics Letters, 55, 279-83.

Lambertini L. (1998), "Process Innovation and the Persistence of Monopoly with Labourmanaged Firms", Review of Economic Design, 3, 359-69.

Lambertini L. - G. Rossini, (1998), "Capital Commitment and Cournot Competition with Labour-Managed and Profit-Maximizing Firms", Australian Economic Papers, 37, $14-21$. 
Levinson K. (2000), "Codetermination in Sweden: myth and reality", Economic and Industrial. Democracy, 21, 457-473.

Martin R.E. (1986) “Quality Choice under Labour Management”, Journal of Comparative Economics, 10, 400-413.

McIntyre R.J. - Dallago B. (Eds.) (2003), Small and Medium Enterprises in Transitional Economies, Palgrave Macmillan, London (2003).

Meade J. (1972), "The Theory of Labour-managed Firms and Profit-sharing”, The Economic Journal, 82 (supp.), 402-28.

Moretto M. - G. Rossini (2003), "Labour Participation", in P. Bianchi - L. Lambertini (eds.), Technology, Information and Market Dynamics: Topics in Advanced Industrial Organization, Cheltenham, UK, Edward Elgar, 81-118.

Mussa M. - D. Rosen (1978), "Monopoly and Product Quality", Journal of Economic Theory, 18, 301-17.

Oczkowski E. (2006), "Nash Bargaining and Co-operatives", Australian Economic Papers, 45, 89-98.

Papandrea F. - R. Albon (2004), "A Model of Employment in the Arts", Australian Economic Papers, 43, 277-87.

Pencavel J. - Craig B. (1994), “The Empirical Performance of Orthodox Models of Firms, Conventional Firms and Workers Cooperatives", Journal of Political Economy, 102, 718-744.

Rossini G. (2005), “Outsourcing with Labor Management”, Economic System, 29, 455466.

Sertel M. (1982), Workers and Incentives, North Holland, Amsterdam.

Sertel M. (1987), “Workers' Enterprises Are Not Perverse”, European Economic Review, 31, 1619-25.

Sertel M., (1991), "Workers' Enterprises in Imperfect Competition", Journal of Comparative Economics, 15, 698-710.

Sertel M. (1993), “Workers' Enterprises in Price Competition”, Managerial and Decision Economics, 14, 445-49.

Spence A. M. (1975), “Monopoly, Quality and Regulation”, Bell Journal of Economics, 6, 417-29. 
Stephen F. (1982), The Performance of Labour-Managed Firms, St. Martin's Press, New York.

Szymanski S. - S.F. Ross (2002), “Open Competition in League Sports”, Wisconsin Law Review, 2002, 625-656.

Throsby D. (1994a), "The Production and Consumption of the Arts: A View of Cultural Economics", Journal of Economic Literature, 32, 1-29.

Throsby D. (1994b), “A Work-Preference Model of Artist Behaviour”, in A. Peacock - I. Rizzo (eds.), Cultural Economics and Cultural Policies, Kluwer Academic Publishers, Dordrecht, pp. 69-80.

Towse R. ed. (1997), Cultural Economics: The Arts, the heritage and the Media Industries, Edward Elgar, Cheltenham UK.

Unioncamere (2004), Primo Rapporto sulle Imprese Cooperative, Roma.

Vanek J. (1970), The General Theory of Labor-managed Market Economies, Cornell University Press, Ithaca NY.

Vickers J. (1985), "Delegation and the Theory of the Firm”, The Economic Journal, 95, $138-47$.

Vrooman J, (2000), “The Economics of American Sports Leagues”, Scottish Journal of Political Economy, 47, 364-98.

Vrooman J, (2007), “Economics of Sport: Editor's Introduction”, Scottish Journal of Political Economy, 54, 309-13.

Ward B. (1958), “The Firm in Illyria: Market Syndacalism”, American Economic Review, 48, 566-589.

Ward M. E. - Sloane P. J. (2000), "Non-pecuniary Advantages versus Pecuniary Disadvantages: Job Satisfaction among Male and Female Academics in Scottish Universities", Scottish Journal of Political Economy, 47, 273-303.

Williamson O. E (1964), The Economics of Discretionary Behaviour: Managerial Objectives in a Theory of the Firm, Prentice-Hall, Englewood Cliffs N.J..

Zimbalist A. (1992), "Salaries and Performance: Beyond the Scully Model", in P. Sommers (ed.) Diamonds Are Forever. The Business of Baseball, Brookings, Washington, DC. 